\title{
Molecular characterization and expression analysis of two peptidoglycan recognition proteins (CCPGRP5, CCPGRP6) in larvae ontogeny of common carp Cyprinus carpio $\mathrm{L}$. and upon immune stimulation by bacteria
}

Fumiao Zhang ${ }^{\dagger}$, Shijuan Shan ${ }^{\dagger}$, Xiaoyang Xu, Yao Wang, Yonghuan Zhang, Miao Yin ${ }^{*}$ and Guiwen Yang ${ }^{*}$ (D)

\begin{abstract}
Background: Although teleost fish developed acquired immunity firstly in evolution, innate immunity is still very important for them. Innate immunity depends on pattern recognition receptors (PRRs) to distinguish "self" and "non-self", Peptidoglycan (PGN) recognition protein (PGRP) is one of the receptors and it can bind to multiple components of bacterial envelope.

Results: We report the cloning and expression analysis of two PGRPs (Ccpgrp5 and Ccpgrp6) from common carp (Cyprinus carpio L). The Ccpgrp5 gene encodes a protein of 199 amino acid (aa) with PGRP domain, Ami_2 domain and four $\mathrm{Zn}^{2+}$ binding sites required for amidase activity, but without signal peptide and transmembrane domain. The Ccpgrp6 gene encodes a protein of 446 aa with PGRP domain, Ami_2 domain, signal peptide, five $\mathrm{Zn}^{2+}$ binding sites required for amidase activity and two sites for $\mathrm{N}$-glycosylation. The phylogenetic analysis revealed that the CCPGRP5 and CCPGRP6 are closely related to Ctenopharyngodon idella and Danio rerio. Ccpgrp5 and Ccpgrp6 were expressed in all tissues examined including liver, spleen, muscle, oral epithelium, head kidney, gill, skin, gonad, brain, foregut and hindgut and showed different distribution characteristics. During the embryonic and early larval developmental stages of common carp, Ccpgrp6 was detected to be highly expressed at 10 days post fertilization(dpf) and $36 \mathrm{dpf}$, while Ccpgrp5 were hardly detected using Real-time quantitative PCR. After being challenged with Aeromonas hydrophila, Ccpgrp5 in adult common carp was induced and up-regulated in all the tissues, especially in gill and spleen, but not in head kidney, while Ccpgrp6 was up-regulated in all the tissues, especially in liver, head kidney and gill. The varied expression profiling of Ccpgrp5 and Ccpgrp6 indicated they had different roles in the host immune response.

Conclusions: These results indicated the two PGRPs, especially Ccpgrp6, played an important role in the immune defense of common carp during larva development and against Aeromonas hydrophila, providing insight to further exploration of protecting fish against bacteria infectious disease.
\end{abstract}

Keywords: PGRP, Common carp, Larva, Aeromonas hydrophila

\footnotetext{
* Correspondence: yinmiao@sdnu.edu.cn; yanggw@sdnu.edu.cn

${ }^{\dagger}$ Fumiao Zhang and Shijuan Shan contributed equally to this work.

Shandong Provincial Key Laboratory of Animal Resistance Biology, College of

Life Sciences, Shandong Normal University, No. 88 East Wenhua Road, Jinan

250014, People's Republic of China
}

(c) The Author(s). 2019 Open Access This article is distributed under the terms of the Creative Commons Attribution 4.0 International License (http://creativecommons.org/licenses/by/4.0/), which permits unrestricted use, distribution, and reproduction in any medium, provided you give appropriate credit to the original author(s) and the source, provide a link to the Creative Commons license, and indicate if changes were made. The Creative Commons Public Domain Dedication waiver (http://creativecommons.org/publicdomain/zero/1.0/) applies to the data made available in this article, unless otherwise stated. 


\section{Background}

Innate immune system offers germline-encoded immediate protection for the host from pathogen infections and has retained its antimicrobial effectiveness for millions of years in all multicellular organisms [1]. Although fish is the first vertebrate to develop adaptive immunity, they still defend against pathogens depending on the innate immune mechanism primarily until their adaptive immune system has developed, especially their eggs and embryos which are laid and develop in water [2]. Even in adult fish, the function of innate immunity are still irreplaceable in their life $[3,4]$.

Peptidoglycan recognition protein (PGRP) is one of pattern recognition receptors (PRRs) and it can recognize common component of bacterial cell wall such as peptidoglycan (PGN), lipoteichonic acid (LTA), and lipopolysaccharide (LPS) [5]. So it is possible for immune cells to discriminate the pathogens from the host cells.

PGRPs are conserved in most animal species from insects to mammals, containing the Ami_2 domain and PGRP domain [5]. The Ami_2 domain is homologous to type II amidase of bacteria and phage lysozyme, which enable PGRP to interact with pathogens and kill the invading pathogens directly with $\mathrm{Zn}^{2+}$ [6]. The first peptidoglycan recognition protein was found in the blood of Bombyx mori, which can bind to PGN without $\mathrm{Ca}^{2+}$, activate prophenoloxidase cascade and induce humoral melanization $[7,8]$. More than 100 peptidoglycan recognition proteins have been found in all species at present, which are expressed in varied tissues, notably in tissues of the immune system such as bone marrow and peripheral neutrophils of bovine [9], bone marrow and spleen of porcine [10], liver, head kidney and spleen of grass carp [11], spleen and liver of Chinese giant salamander [12]. On one hand PGRPs have amidase activity to hydrolyze the lactyl-amide bond between MurNAc and 1-Ala in the PGN and on the other hand trigger the Toll or Immune deficiency (Imd) signal transduction pathway to generate antimicrobial peptides [5]. As to vertebrate PGRPs, there are four paralogs in mammals. They usually presented disulphide-linked homo and heterodimers with both recognition and effector functions [13]. PGLYRP-2 secreted from liver into blood is an $\mathrm{N}$-acetylmuramoyl-L-alanine amidase and PGLYRP-1, PGLYRP-3 and PGLYRP-4 are also bactericidal or bacteriostatic proteins which were different from known vertebrate antimicrobial [14]. Recent studies indicated that PGRP could induce oxidative, thiol, and metal stress responses simultaneously in bacteria through three independent pathways [15].

Among fish species, PGRP molecules were found in zebra fish (Danio rerio) [16, 17], rockfish (Sebastes schlegeli) [18], rock bream (Oplegnathus fasciatus) [19], large yellow croaker (Pseudosciaena crocea) [20], channel catfish (Ictalurus punctatus) [21], green-spotted pufferfish
(Tetraodon nigroviridis) [16], grass carp (Ctenopharyngodon idella) [11, 22, 23], rainbow trout (Oncorhynchus mykiss) [24, 25], turbot(Scophthalmus maximus) [26], tongue sole (Cynoglossus semilaevis) [27], and red drum (Sciaenops ocellatus) [28]. The sequence of PGRP5 and PGRP6 gene are also cloned from common carp (Cyprinus carpio). Among them, three types of PGRP were identified including PGRP2, PGRP5 and PGRP6, with only PGRP-2 homologous to mammal PGLYRP2, while PGRP5 and PGRP6 are found only in teleost fish [21]. Ccpgrp5 and Ccpgrp6 of common carp are short PGRP and long PGRP molecules respectively, but the response and expression of Ccpgrp5 and Ccpgrp6 are not known. In other fish, the PGRPs take the important role in resistance of bacteria. Firstly, previous studies demonstrated that teleost fish PGRP had both amidase and bactericidal activities in one molecule, including SsPGRP-L1 and SsPGRP-L2 from the rock fish, PGLYRP-2, PGLYRP-5 and PGLYRP-6 from zebrafish [18]. Secondly, fish PGRP played immunomodulatory roles in the immune response to bacteria, such as OmPGRP-L1 and OmPGRP-L2 from rainbow trout, PGRP-SC2 from rock bream. As for the distribution of fish PGRPs, they were expressed ubiquitously in many tissues, and their constitutive expression levels were higher in classical immune tissues than in mucosal tissues. Furthermore, the up-regulation of PGRP could be induced by bacterial challenge. For instance, SmPGRP2 from turbot induced by Streptococcus iniae and Vibrio anguillarum, and RbPGRP-SC2 from rock bream induced by Edwardsiella piscicida, Streptococcus iniae. However, only a few studies have investigated the expression profiling of PGRPs in larvae ontogeny and its response upon immune stimulation by Aeromonas hydrophila in vertebrates including teleost fish.

Carp is one of the most popular cultured fish in China and the diseases caused by Aeromonas hydrophila can do great harm to carp aquaculture. Aeromonas hydrophila is resistant to antibiotics attributed to the indiscriminate use of antibiotics in aquaculture and plasmid or horizontal gene transfer [29-31]. However, innate immune system offers germline-encoded immediate protection for the host from infections and has retained its antimicrobial effectiveness for millions of years with no frequent emergence of resistant strains. Here we cloned two carp PGRPs, named as Ccpgrp5 and Ccpgrp6, and showed their expression profiling in larvae ontogeny, normal adult tissues and adults tissues exposed to Aeromonas hydrophila.

\section{Results}

cDNA sequence of Ccpgrp5 and Ccpgrp6

Using 3'- and 5'-RACE, we identified two PGRP candidates from the total RNA of common carp, the Ccpgrp5 and the Ccpgrp6. The cDNA of Ccpgrp5 (GenBank Accession number MF818332) is $757 \mathrm{bp}$ in length 


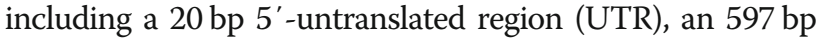
ORF and a $140 \mathrm{bp} \mathrm{3'-UTR,} \mathrm{which} \mathrm{encodes} \mathrm{a} \mathrm{protein} \mathrm{of} 199$ amino acids with a predicted isoelectric point (PI) of 7.095 (Fig. 1). The sequence of CcPGRP5 shared 100\% sequence identities and 96\% query cover with previous PGRP5 sequence of Cyprinus carpio (KT224436). The full-length Ccpgrp6 cDNA (GenBank accession number MG272264) amplified from the spleen of common carp was $1561 \mathrm{bp}$ in length, including a 54 bp 5 '-untranslated region (UTR), an open reading frame (ORF) of $1383 \mathrm{bp}$ and a $124 \mathrm{bp} 3$ '-UTR. The ORF of Ccpgrp6 encoded a putative protein of 461 amino acids with a predicted isoelectric point (PI) of 6.467 (Fig. 2).The sequence of CcPGRP6 shared $98 \%$ sequence identities and 99\% query cover with previous PGRP6 sequence of Cyprinus carpio (KU642466).

\section{Homology alignment and phylogenetic analysis}

Sequence analysis of CcPGRP5 and CcPGRP6 indicated that they were highly homologous to PGRPs from other species, especially at their C-terminals. As a short PGRP, CcPGRP5 is highly homologous to grass carp (Ctenopharyngodon idella) PGRP5 (88\%) and zebra fish (Danio rerio) PGRP5 (84\%). As a member of long PGRP, the amino acid sequence of CcPGRP6 are homologous to grass carp (Ctenopharyngodon idella) PGRP6 (84\%) and zebrafish (Danio rerio) PGRP6 (73\%).

Sequence analysis indicated that CcPGRP5 had four $\mathrm{Zn}^{2+}$ binding sites (His56, Tyr90, His164, Cys172) for amidase activity and three conserved binding sites (Arg83, Gly105, Trp106) for recognizing DAP-type peptidoglycan specifically (Figs. 1 and 3). Analysis using

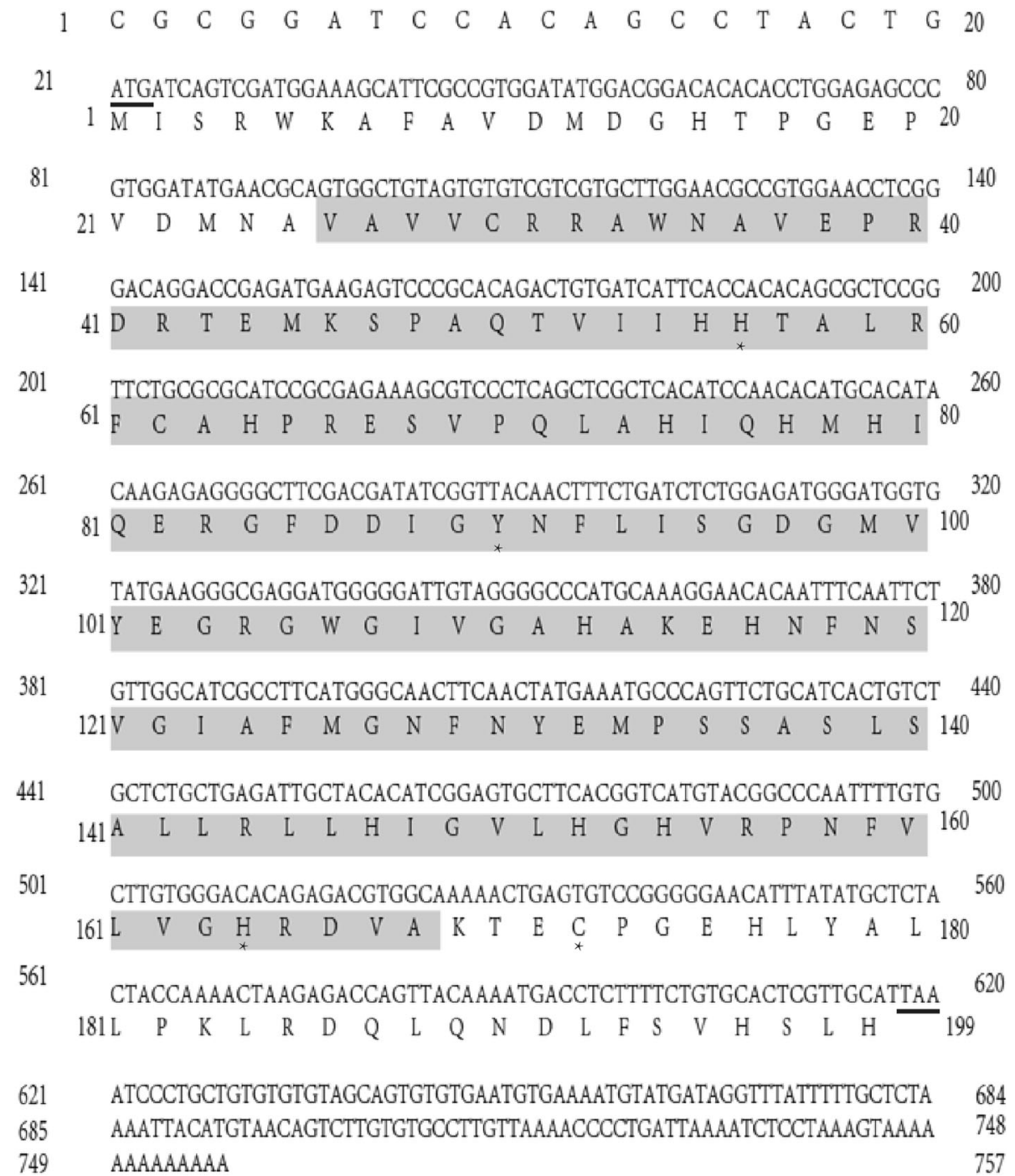

Fig. 1 Nucleotide and deduced amino acid sequences of common carp peptidoglycan recognition protein5, Ccpgrp5. The translation start codon ATG and the termination codon TAA are indicated under line. The PGRP domain is shown in grey (26-168aa). Zn $\mathrm{n}^{2+}$ binding sites (H56, Y90, H164, C172) are marked with asterisk 


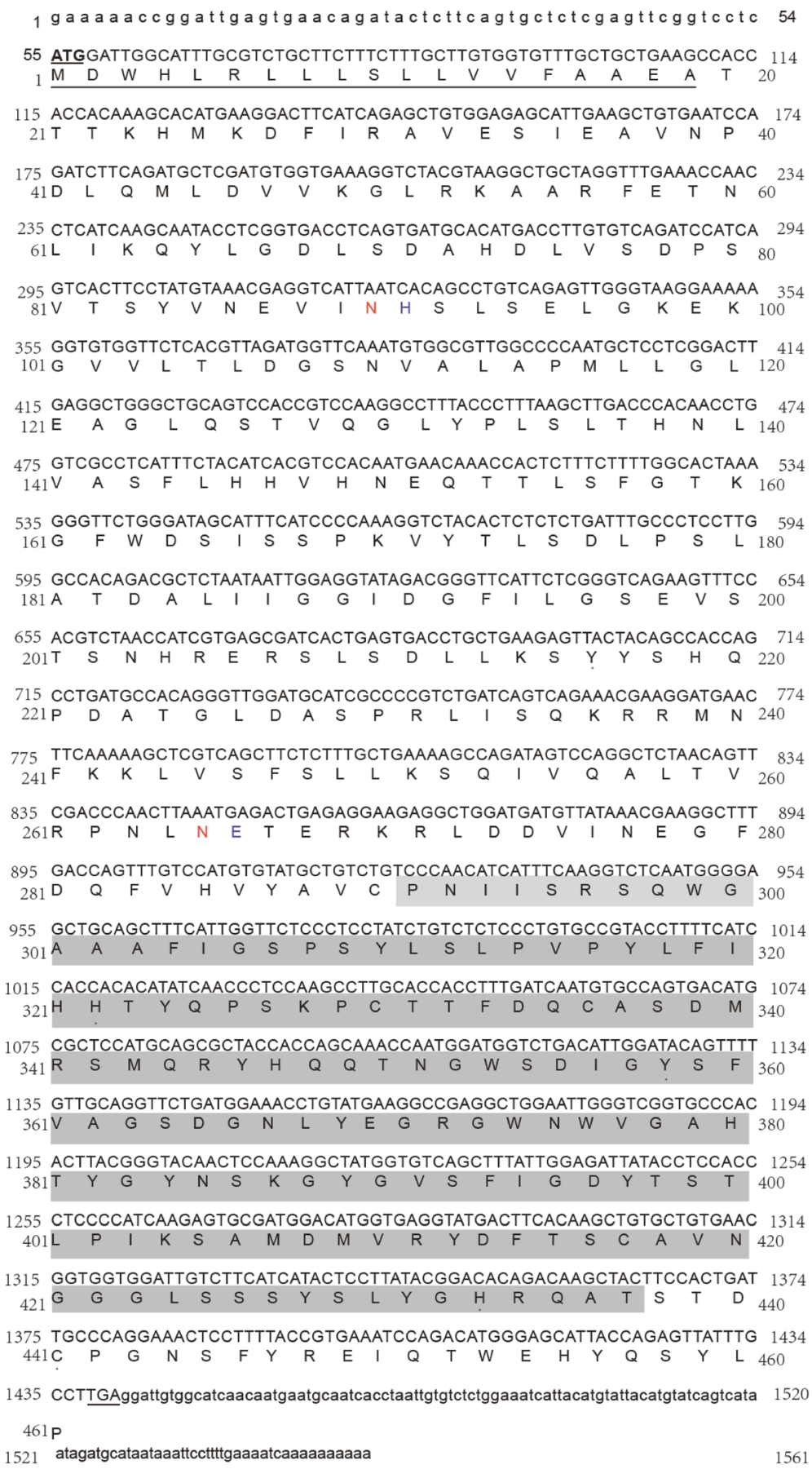

Fig. 2 Nucleotide and deduced amino acid sequences of common carp peptidoglycan recognition protein 6, Ccpgrp6. The translation start codon ATG and the termination codon TAA are indicated in dotted line. The sequence of signal peptide is indicated under line (1-19aa). The PGRP domain is shown in grey (291-437aa). $\mathrm{Zn}^{2+}$ binding sites (Y216, H322, Y358, H433, C441) are marked with asterisk. The predicted N-glycosylated sites are highlighted in red (Asparagines) and blue (Asn-Xaa-Ser/Thr sequences)

SignalP 4.0 server indicate that CcPGRP5 has no signal peptide and no transmembrane domain to function in cytosol. Using the SMART program, the CcPGRP5 was found to comprise a PGRP domain (26-168 aa) and an Ami-2 domain (37-174 aa). To investigate the evolutionary relationships of CCPGRP5 with that of other species, a phylogenetic tree was constructed. The results showed that CCPGRP5 is most similar to grass carp (Ctenopharyngodon idella) PGRP5 and Zebrafish (Danio rerio) PGRP5 (Fig. 4). 


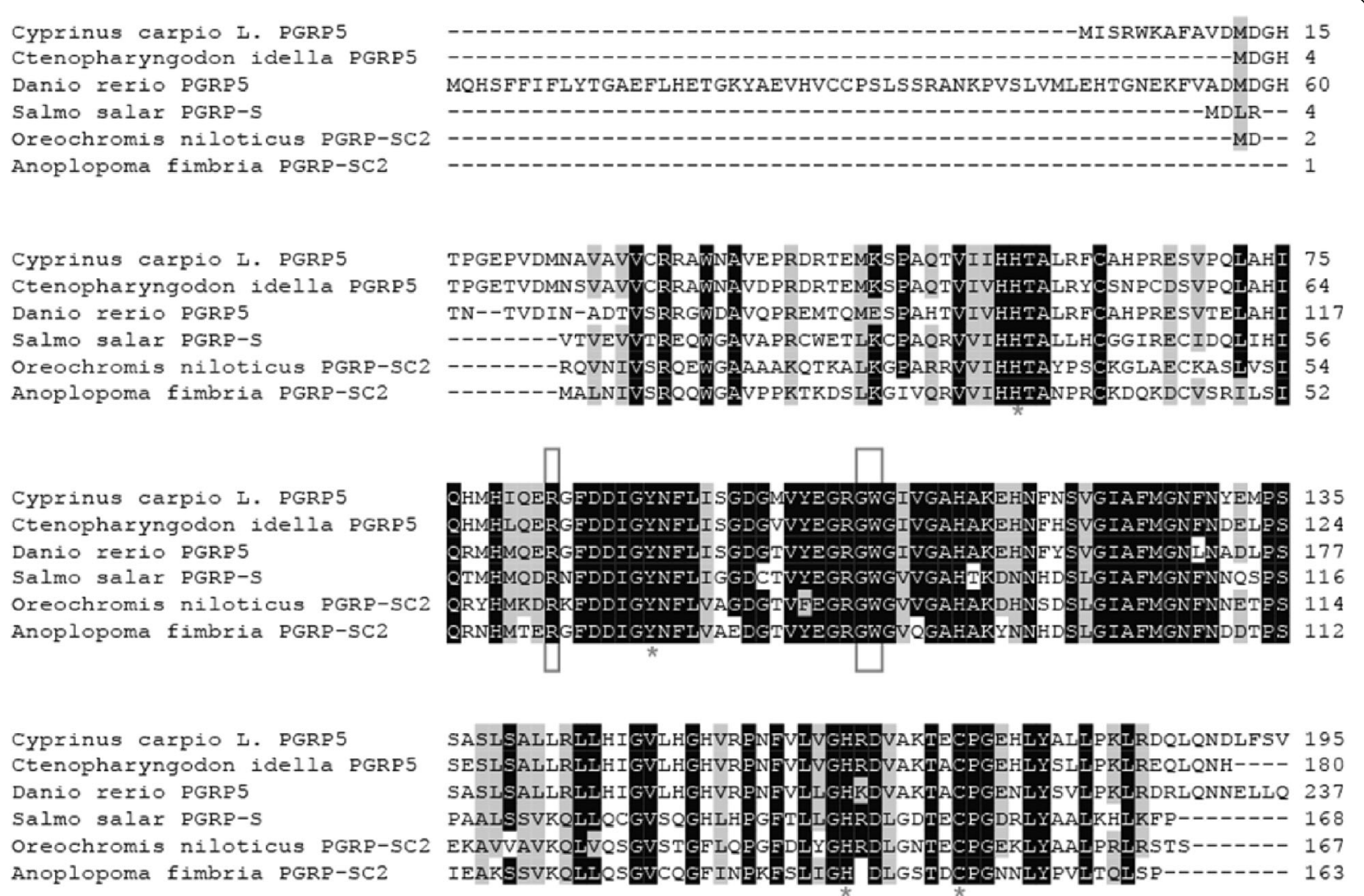

Fig. 3 Multiple sequence alignment of the deduced CCPGRP5 with that of other five fish species. The amino acid sequences of PGRP5/PGRP-SC in Cyprinus carpio (MF818332), Ctenopharyngodon idella (AFE8096), Danio rerio (NP_001037786), Salmo salar (BT049722), Oreochromis niloticus (XP_003441739) and Anoplopoma fimbria(ACQ58764) are deduced from cDNA. Residues conserved in all species are shaded in black. The right number represent the amino acid position in the corresponding species. The conserved amino acid residues (R83, G105 and W106) shown in box are sites for recognizing DAP-type peptidoglycan specifically. $\mathrm{Zn}^{2+}$ binding sites (H56, Y90, H164, C172) are marked with asterisk

Multiple sequences alignment with other long PGRPs, including zebrafish (Danio rerio) PGRP6 and PGRP2, grass carp (Ctenopharyngodon idella) PGRP6, opossu (Monodelphis domestica) PGRP1, platypus (Ornithorhynchus anatinus) PGRP-L, red drum (Sciaenop socellatus) PGRP-2, rockfish (Sebastes schlegelii) PGRP-L2, and puffer fish (Tetraoden migroviridis) PGRP-L showed that the C-terminal of PGRP, which was characteristic of amidase activity, were highly conserved. However, $\mathrm{N}$-terminals in these species did not show significant homologous. Sequence analysis indicated that CcPGRP6 has five $\mathrm{Zn}^{2+}$ binding sites (Tyr216, His322, Tyr358, His433, Cys441) for amidase activity, three conserved binding sites (Gly452, Trp453, Arg472) for recognizing DAP-type peptidoglycan specifically, and conserved Cys residues that form disulfide bonds (Fig. 5). CcPGRP6 contains a PGRP domain (291-437 aa) and an Ami_2 domain (303-443 aa). Analysis using SignalP 4.0 server indicate that CcPGRP6 may function as a secreted protein because it has predicted signal peptides composed of 19 amino acid residues (1-19 aa) and no transmembrane domain. To investigate the evolutionary relationships of CCPGRP6 with other species, a phylogenetic tree was constructed. The results showed that CcPGRP6 is clustered closely with the PGRP6 of grass carp (Ctenopharyngodon idella) and Zebrafish (Danio rerio) (Fig. 6).

\section{Constitutive expression of the Ccpgrp5 and Ccpgrp6}

To investigate the tissue-dependent expression pattern, we performed qRT-PCR analysis using gene-specific primers for Ccpgrp5 and Ccpgrp6. The expression of the Ccpgrp5 and Ccpgrp6 were detected in almost all examined tissues of normal adult carp with varied expression levels in different tissues. Expression of Ccpgrp5 was found to be highest in the brain and gonad, and then in decreasingly order in skin, gill, head kidney, oral epithelium, hindgut, muscle, spleen, liver and foregut (Fig. 7a). In contrast, Ccpgrp6 was strongly expressed in the spleen, liver and gill, but weakly expressed in the foregut, head kidney, skin, oral, brain, gonad and muscle (Fig. 7b). 


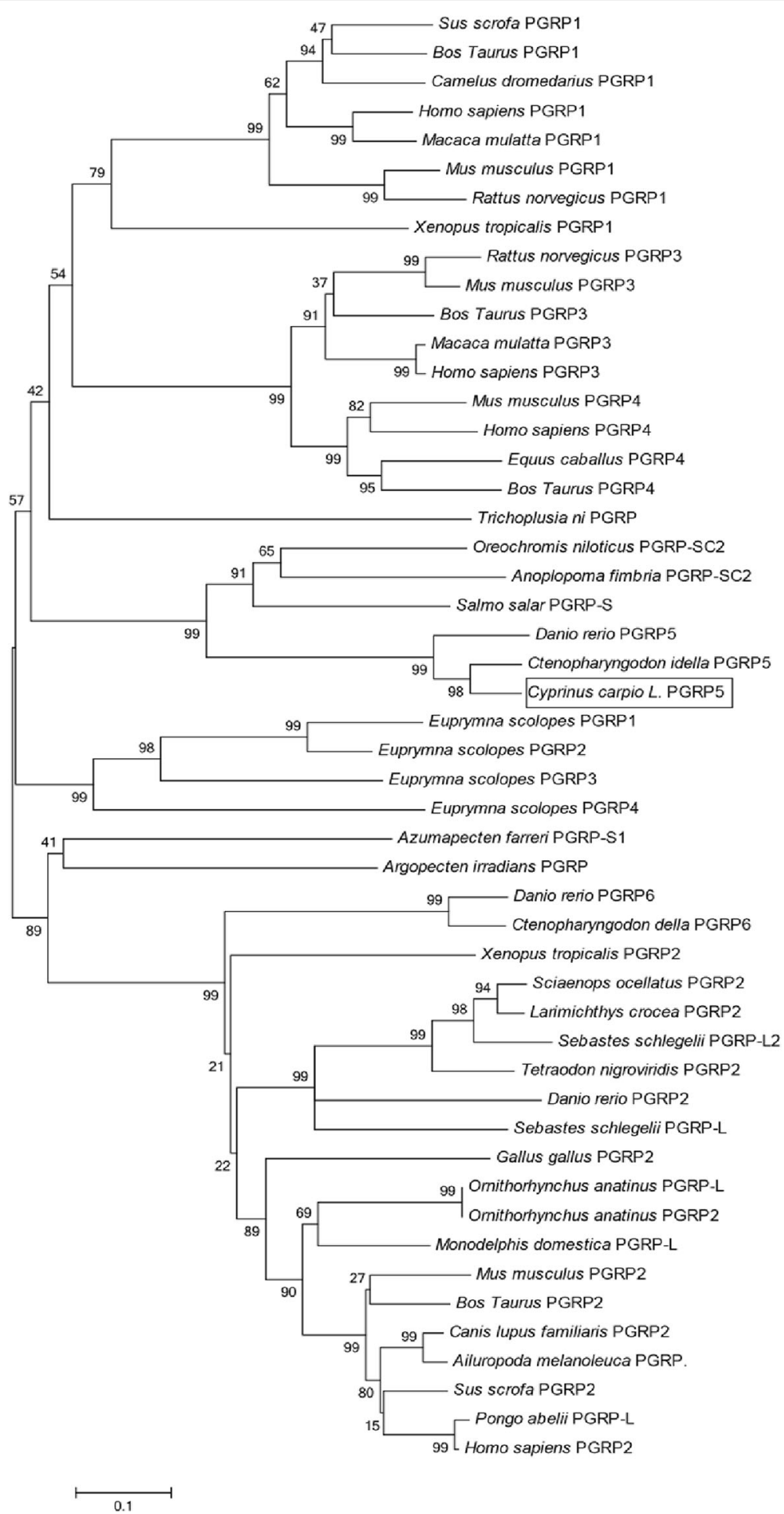

Fig. 4 Phylogenetic tree analysis of CCPGRP5 with all known PGRPs from the other species. Phylogenetic tree was obtained from a CLUSTALW alignment and MEGA 6.0 Neighbor-Joining of 50 sequences. The bar indicated the distance

Further study on the constitutive expression of the two Ccpgrps gene in embryo and early larvae of common carp from 1 to 36 days post fertilization (dpf) showed that though the expression of Ccpgrp6 was hardly detected at 1 dpf and 2 dpf, Ccpgrp 6 was relatively highly expressed at 10 $\mathrm{dpf}$ and $36 \mathrm{dpf}$ (Fig. 7c). However, the expression level of Ccpgrp5 was too low to be detected in embryo and early larva of common carp by Real-time quantitative PCR. 

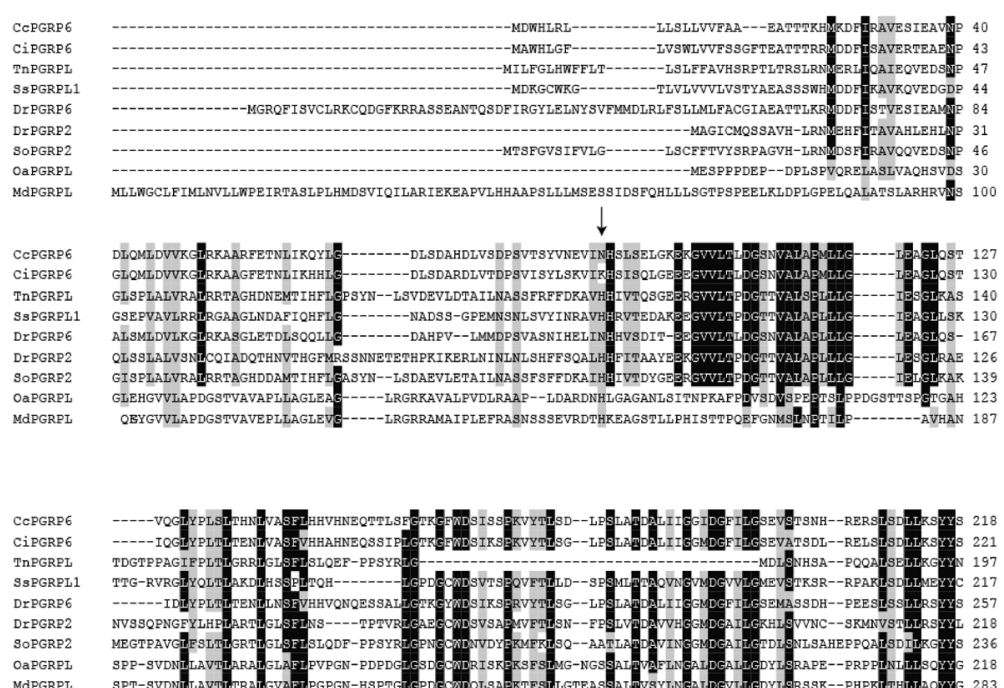

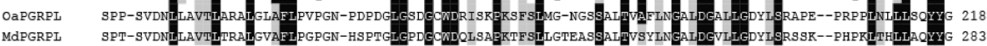
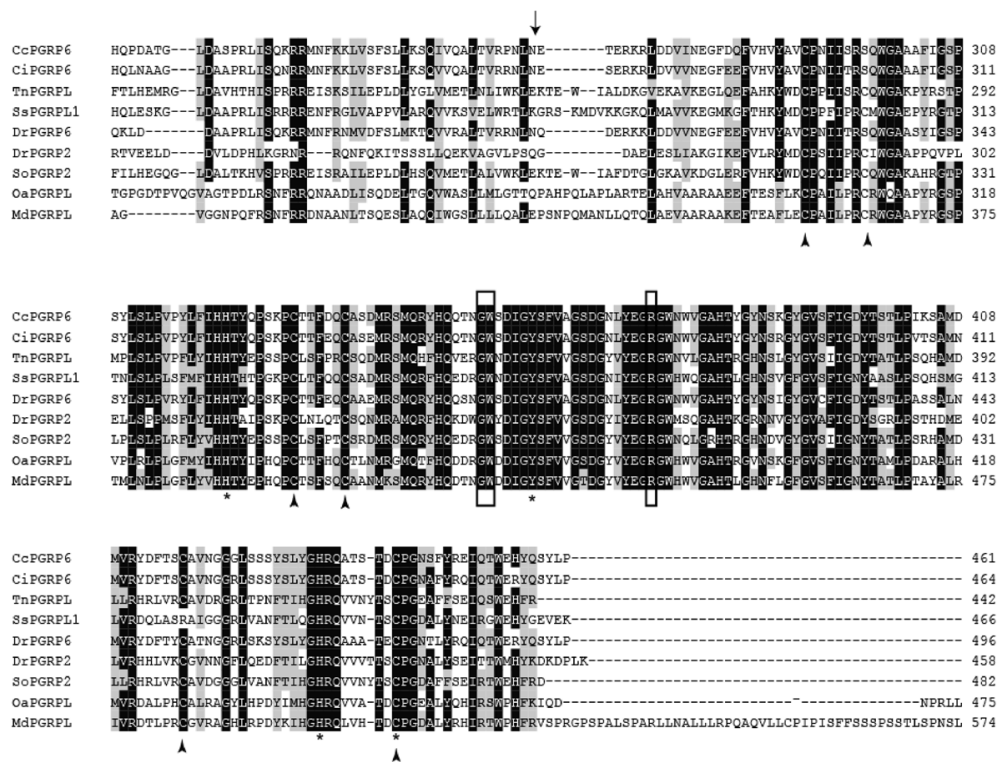

Fig. 5 Multiple sequence alignment of the deduced CCPGRP6 with that of other five fish species. The amino acid sequences of PGRP6/PGRP2/PGRP-L/ L1 in Cyprinus carpio (MG272264), Ctenopharyngodon idella (ADL41 1866), Tetraodon nigroviridis (CAG061 14), Sebastes schlegelii (ADC93708), Danio rerio (NP_001038631, NP_001038687), Sciaenop socellatus (GU126381), Ornithorhynchus anatinus (XP-001506175) and Monodelphis domestica (XP-001363587) are deduced from cDNA. Residues conserved in most species are shaded in black. The right number represent the amino acid position in the corresponding species. The conserved amino acid residues (G452, W453 and R472) shown in box are sites for recognizing DAP-type peptidoglycan specifically. Z $\mathrm{n}^{2+}$ binding sites (Y216, H322, Y358, H433, C441) are marked with asterisk.Conserved cysteine residues to form disulfide bonds are marked with arrow

\section{Expression profiles of Ccpgrp5 and Ccpgrp6 in common carp challenged by $A$. hydrophila}

Common carp was challenged with A.hydrophila in order to determine the expression profiles of PGRPs in response to bacterial infections. The two PGRPs exhibited distinctive tissue expression profiles. The expression of Ccpgrp5 was significantly upregulated and reached the highest in the gill and liver at 12 hpi (hours post injection), with 80.5-fold and 2.9-fold higher than the control group respectively $(p<0.01)$, while the highest expression detected in spleen, foregut and hindgut appeared at $5 \mathrm{dpi}$ (days post injection), with 12.1-fold in spleen, 2.7-fold in foregut and 2.5-fold in hindgut $(p<0.01$ or $p<0.001$ for all). Meanwhile, no significant fold increase were observed in head kidney and very minor increase in skin (about 2-fold), but decreased expression of Ccpgrp5 in these two tissues at both 1dpi and 2dpi (Fig. 8). Compared with 


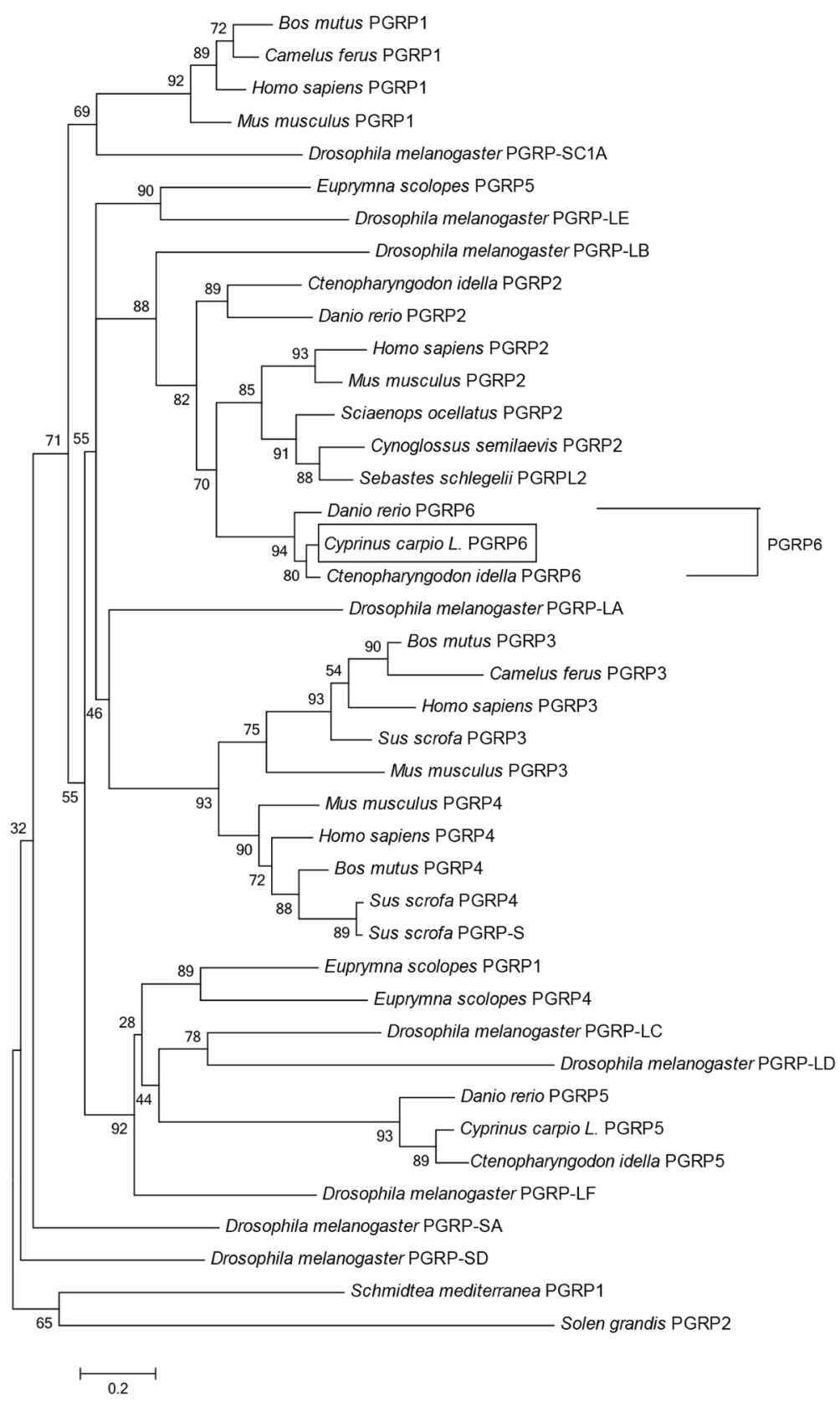

Fig. 6 Phylogenetic tree analysis of CCPGRP6 with all known PGRPs from the other species. Phylogenetic tree was obtained from a CLUSTALW alignment and MEGA 6.0 Neighbor-Joining of 50 sequences. The bar indicated the distance

Ccpgrp5, the expression of Ccpgrp6 in most tested tissues was different. In gills, the expression level of Ccpgrp6 mRNA after A.hydrophila challenge was up-regulated highest with 8 -fold at $3 \mathrm{hpi}$, which is earlier than Ccpgrp5, but the fold change was moderate. In head kidney, the induced expression of Ccpgrp6 was so obvious that their highest level reached 7.9-fold at 3hpi. The mRNA expression of Ccpgrp6 after A.hydrophila challenge was detected highest in the other three tissues including liver, skin and spleen at $12 \mathrm{hpi}$, with 9.7-fold, 2.9-fold and 2.9-fold higher expression than the control group respectively $(p<0.01$ or $p<0.001$ for all). In foregut and hindgut, the expression of Ccpgrp6 was induced for a longer period of time with higher fold change (about 6-fold) than that of CcPGRP5 (Fig. 9). The results indicated that Ccpgrp6 might play a more important role in both system immune function and mucosal immune function of common carp challenged by A.hydrophila. 


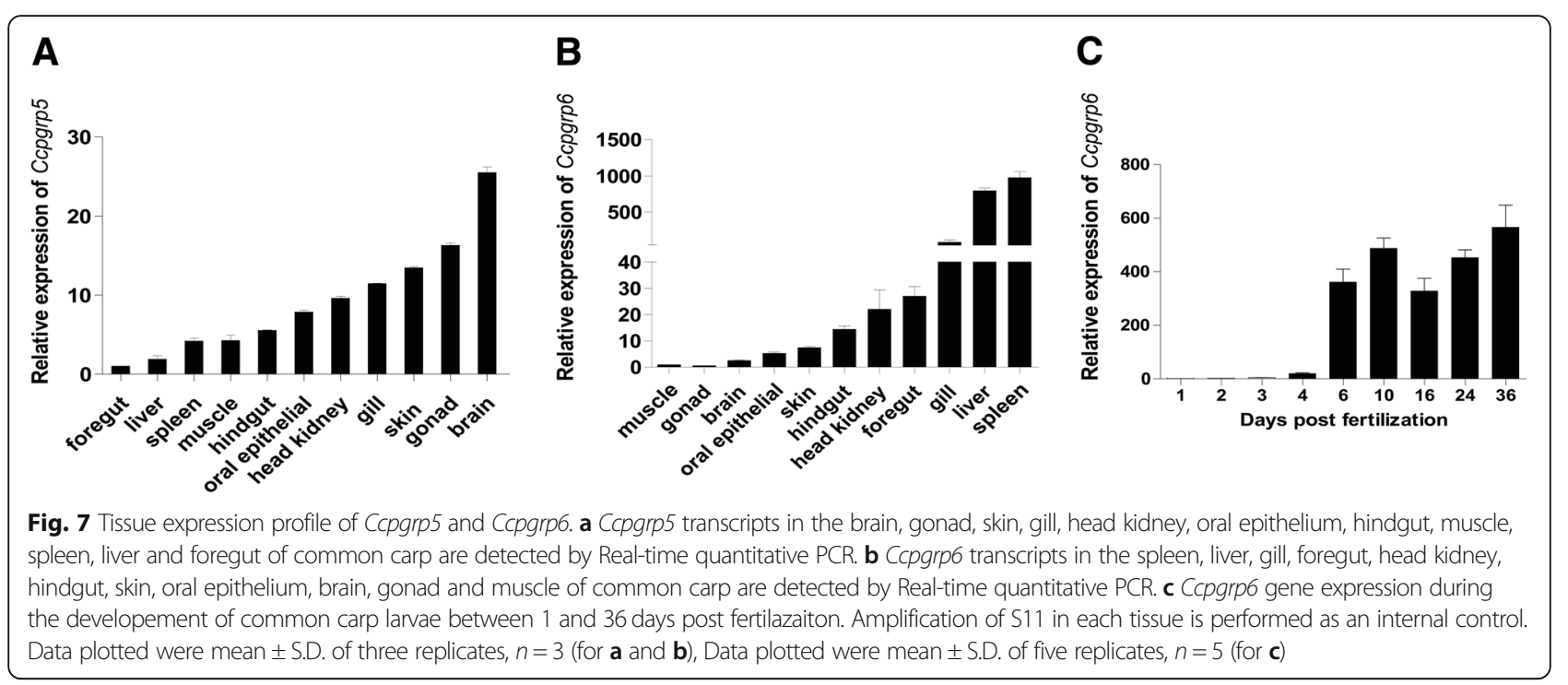

\section{Discussion}

The structure of peptidoglycan recognition protein (PGRP) is highly conserved from invertebrates to vertebrates. Both CcPGRP5 and CcPGRP6 have conserved domain and amino acid residues in sequences which are related with their function. The study of common carp showed that both CcPGRP5 and CcPGRP6 have PGRP domain and Ami_2 domain. The Ami_2 domain at C terminal of most of PGRP is a type 2 amidase domain, which is homologous to the type 2 amidase of bacteriophages and bacteria. In addition, sequences alignment showed that $\mathrm{Zn}^{2+}$ binding sites existed in both CcPGRP5 (His56, Tyr90, His164 and Cys172) and CcPGRP6
(Tyr216, His322, Tyr358, His433, Cys441), which indicates that they may have $\mathrm{Zn}^{2+}$ dependent amidase activity. Furthermore, the conserved binding sites for specific recognition of DAP-type peptidoglycan also existed in CcPGRP5 (Arg83, Gly105, Trp106) and CcPGRP6 (Gly452, Trp453, Arg472). As we know, Dap-type peptidoglycans are components of many Gram-negative and some Gram-positive bacteria. Long PGRP, such as Drosophila membrane PGRP-LC, recognize Dap-type peptidoglycans and activates both the imd pathway and the proPO cascade [32]. Besides, CcPGRP6 may function as a secreted protein because it has a signal peptide and no transmembrane, while CCPGRP5 may be present in






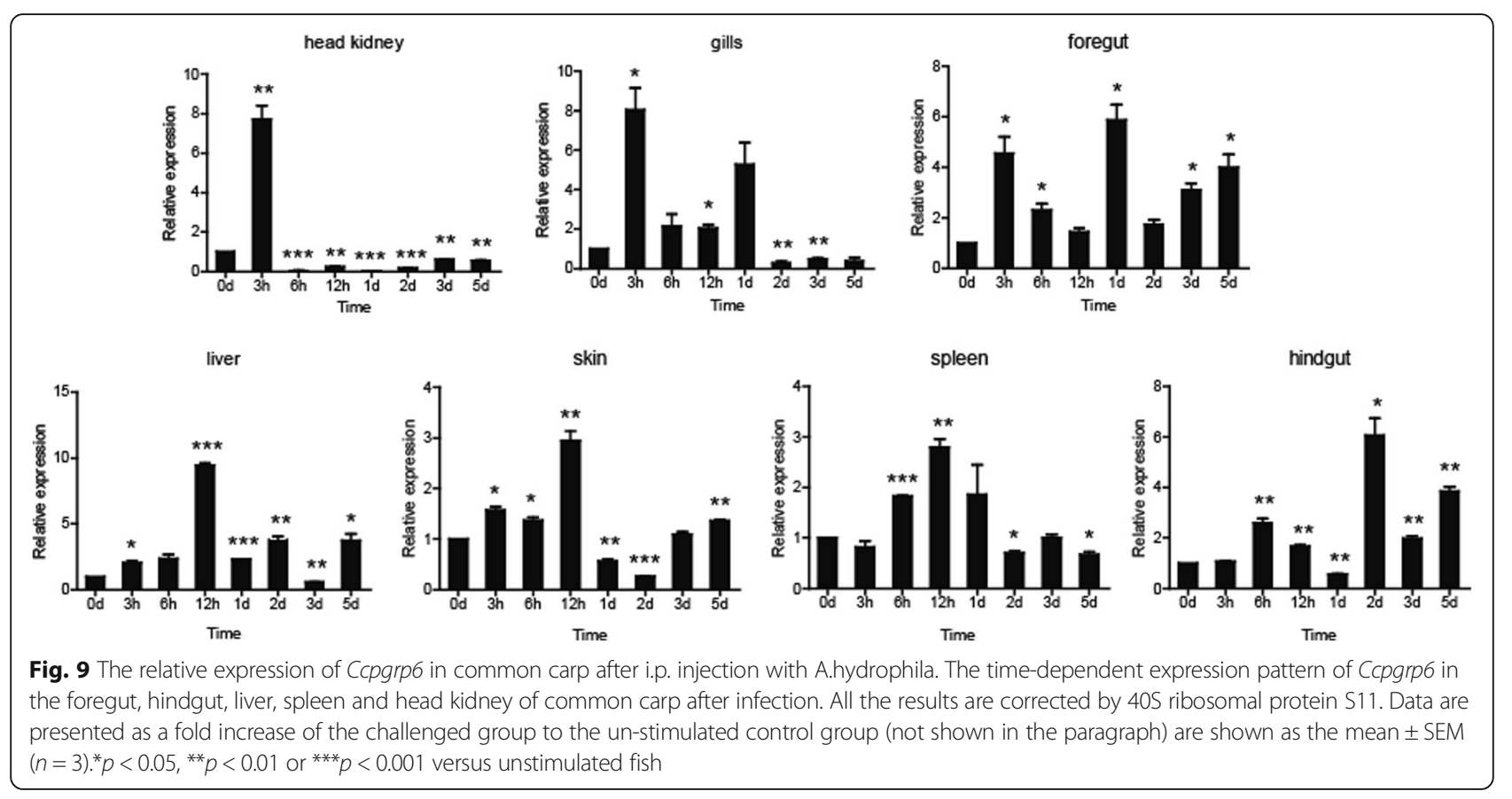

the cytosol due to the lack of signal peptide and transmembrane.

PGRP is usually expressed in blood cells, such as hemolymph of silkworm and arthropods, and neutrophils of mammals $[8,13]$. However, the expression of PGRP in other tissues could also be detected, such as fat bodies of insects, gills, muscles, gonads, hepatopancreas of mollusks [33], liver, intestine, stomach in Amphibian and head kidney, spleen, gill, intestine, skin, liver of fish, Furthermore, PGRP of most these tissues demonstrated amidase activity. As for the tissue specific expression patterns of Ccpgrp5 and Ccpgrp6, the two molecules are very different. Firstly, Ccpgrp6 is substantial highly expressed in the immune related tissues such as spleen and liver, followed by the expression in gill and foregut which directly contacts pathogens, and then muscle and gonad etc. However, the highest expression of Ccpgrp5 is in brain, followed by gonad, skin and gill, with the expression in liver and spleen being less than that of muscle, hindgut, oral epithelial and head kidney. The expression variance among different tissues is smaller for Ccpgrp5 than that for Ccpgrp6. Brain is the main viral target tissues and the gonad used to transmit the virus vertically even in teleost. The study of European sea bass infected with viral nervous necrosis virus (VNNV) in the brain showed that upregulation of interferon (IFN) and different IFN-stimulated genes could be induced in the brain and the gonad. They thought the brain innate immune response is unable to clear the virus and pointed to the importance of gonad immunity to control the dissemination of VNNV to the progeny [34]. Demonstration of the constitutive expression of Ccpgrp in common carp tissues from this study indicated that the Ccpgrp6 may play an important role in the basic immune protection of carp, while the role of Ccpgrp5 may be completely different. The comparatively higher expression of Ccpgrp5 in brain and gonad might indicated that this molecule may have important role in the function of these two tissues. Actually, Except for Ccpgrp5, some other immune-related gene including Rig-1 like receptor [35], Toll like receptor [36], XBP-1 [37] are all expressed in gonad. In mammals, It was widely accepted that the process of ovulation is similar to that of inflammation, many genes expressed in the gonad involved in the inflammatory response are also involved in the ovulation process.

A. hydrophila is a Gram-negtive bacterium. The Ccpgrp5 and Ccpgrp6 of carp challenged by A.hydrophila can be induced in different tissues for varied period of time. In previous studies, the PGRP5 in kidney cells of grass carp could be induced by pathogenic factors such as PGN, LTA and poly I:C [11]. In this experiment, although the expression level in gills and spleen of normal carp are not the highest compared with other tissues, the increase of Ccpgrp5 expression in gills and spleens of carp after A.hydrophila challenge is more higher. It was nearly 80 -fold increase in gills at $3 \mathrm{~h}$ post injection (hpi) and 12.1-fold in spleen at 12 hpi respectively. As to Ccpgrp6, the expression increase was not as high as that of Ccpgrp5. It was 
around 6 -fold $\sim 10$-fold in head kidney, gills, foregut, liver and hind gut. However, it needs to be considered that the basic expression of Ccpgrp6 is relatively higher in tissue of spleen, liver, gill and even foregut of normal carp, so the amount of induced production of Ccpgrp6 during A.hydrophila stimulation is considerable.

Fish in aquatic environment are facing survival challenges from pathogenic microbes in the water environment. The immune function of adult fish plays an important role in defending against pathogenic bacteria. Due to the unknown involvement of CCPGRP for the establishment of immunity in the phase of egg and larvae in fish, this study examined the expression of two Ccpgrp in the early embryos of carp. The results showed that the Ccpgrp5 expression could be hardly detected at 1,2,3,4 days post fertilization (dpf) and the expression of Ccpgrp6 began to increase significantly at $6 \mathrm{dpf}$, then the expression level reached to the first peak at $10 \mathrm{dpf}$, followed by a slightly decrease at $16 \mathrm{dpf}$ and $24 \mathrm{dpf}$, and finally reached the highest expression level at 36dpf. The Ccpgrp6 expression profile in larvae of common carp indicated that it might involve in the defense against pathogens in early development stage in aquatic environment. In contrast, Ccpgrp5 could not be detected during the examined development stage. These results were different with what were reported for large yellow croaker and zebra fish. In large yellow croaker, PGRP2 expressed highly in unfertilized egg and kept at very low expression level during larvae [20]. In zebrafish, PGLYRP-2 is strongly expressed in the egg and both PGLYRP-2 and PGLYRP-5 are expressed in the developing embryo. On the contrary, PGLYRP-6 protein could not be detected in the eggs or in the early stages of development of zebrafish [16]. Due to the limited study of PGRP family in egg and larvae of fish, the variance of PGRP between different fish species needs further study.

\section{Conclusion}

This study investigated the structure, evolutionary relationship and expression characteristics of two PGRP genes from common carp. Both Ccpgrp5 and Ccpgrp6 have the conserved PGRP domain and Ami_2 domain and they are highly homologous to the short and long PGPRs in all the vertebrates and invertebrates respectively. The constitutive expression of Ccpgrp5 and Ccpgrp6 in various tissues of adult carp and during early larval ontogeny implies their possible relevance to immune function of common carp and indicated the different role and activation pathway between the two CcPGRPs. Moreover, the up-regulated expression of Ccpgrp5 and Ccpgrp6 strongly indicates that they play a significant role in innate immune defense against bacteria.

\section{Methods \\ Ethics statement}

The protocol was approved by the Animal Experimental Ethics Committee of Shandong Normal University (Permit Number: AEECSDNU2017004).

\section{Fish rearing}

Healthy common carp, Cyprinus carpio L. (180 g on average) were obtained from the Fresh Water Fishery Research Institute of Shandong Province. Carp were maintained at $20-25^{\circ} \mathrm{C}$ in recirculating water and fed twice a day with commercial feed for more than 2 weeks before experimental use [38-40]. The tissue samples, including foregut, liver, spleen, muscle, hindgut, oral epithelial, head kidney, gill, skin, gonad and brain, were obtained from normal common carp, and separately frozen in liquid nitrogen until further use for RNA extraction [41-43].

To examine the expression profiles of common carp PGRPs during ontogeny, four pairs of parent fish were selected for artificial propagation. Fertilized eggs were incubated in water reservoir at $28-30{ }^{\circ} \mathrm{C}$ with sufficient oxygen [1,44]. After fertilization, 5 replicates of developmental samples were collected at 1,2 , $3,4,6,10,16,24$ and $36 \mathrm{dpf}$ (days post fertilization) for total RNA isolation [16].

\section{Bacterial challenges in vivo}

A. hydrophila used in the study was obtained from China Center for Type Culture Collection and incubated in Luria-Bertani medium at $28^{\circ} \mathrm{C}$ overnight under continuous shaking. Adult common carp were anaesthetized and inject intraperitoneally with $5 \times 10^{7}$ $\mathrm{cfu} / \mathrm{ml}$ formalin-inactivated $A$. hydrophila, while control groups were injected with phosphate buffered saline (PBS, pH 7.4) [16]. At $3 \mathrm{~h}, 6 \mathrm{~h}, 12 \mathrm{~h}, 1 \mathrm{~d}, 2 \mathrm{~d}, 3 \mathrm{~d}$ and $5 \mathrm{~d}$ post injection, three individuals in each group were euthanized and sampled for total RNA extraction following the procedures described in previous studies $[35,45]$. The fish were euthanatized by immersion in a solution of Tricaine Methane Sulfonate (MS-222, Sigma Aldrich) at a concentration of $100 \mathrm{mg} / \mathrm{l}$ of water and sampled, all procedures performed under anesthesia and all efforts were made to minimize fish suffering. The fish after the study were disinfected, sealed and treated according to the guidelines of the protocol approved by the Animal Experimental Ethics Committee of Shandong Normal University (Permit Number: AEECSDNU2017004). The collected tissues includes gill, liver, skin, spleen, hindgut, foregut and head kidney. Total RNA was 
extracted (Tiangen) and reverse transcribed to cDNA (Tiangen). The isolated RNA was measured by UV-spectrophotometer to determine the concentration and quality. To prepare 1st strand cDNA, $2 \mu \mathrm{g}$ of total RNA treated with $2 \mu \mathrm{l}$ gDNase buffer was subjected to reverse transcription in $30 \mu \mathrm{l}$ reactions by using the FastQuent RT Kit (Tiangen) according to the protocol. Finally, the synthesized cDNA was kept at $-20^{\circ} \mathrm{C}$ for further analysis $[35,45]$.

\section{Cloning and analysis of Ccpgrp5 and Ccpgrp6 cDNA}

Amplification of the cDNA fragment of Ccpgrp5 from the spleen of common carp were performed as follow: the specific primers were designed based on the conserved regions of the sequence of PGRP5 in fish species. PCR amplification was performed with the following condition: $94^{\circ} \mathrm{C}$ for $3 \mathrm{~min}$, followed by 32 cycles of $94{ }^{\circ} \mathrm{C}$ for $30 \mathrm{~s}, 60^{\circ} \mathrm{C}$ for $30 \mathrm{~s}$, and $72{ }^{\circ} \mathrm{C}$ for $40 \mathrm{~s}$. The PCR products were ligated into the pMD18-T vector, then was subsequently transformed into competent $E$. coli $\mathrm{DH}-5 \alpha$ for sequencing. The full-length of the Ccpgrp5 were obtained by RACE (rapid amplification of the cDNA ends) using the $3^{\prime}$-full and $5^{\prime}$-full RACE core set (TaKaRa). The primers used are shown in Table 1. Amplification of Ccpgrp6 was performed following the same protocol as for Ccpgrp5. PCR of Ccpgrp6 was performed with the following condition: $94{ }^{\circ} \mathrm{C}$ for $3 \mathrm{~min}$, followed by 32 cycles of $94{ }^{\circ} \mathrm{C}$ for $30 \mathrm{~s}, 60^{\circ} \mathrm{C}$ for $30 \mathrm{~s}$, and $72{ }^{\circ} \mathrm{C}$ for $60 \mathrm{~s}$. The primers used are shown in Table 1.

The structural domains of CcPGRP5 and CcPGRP6 were analyzed using the SMART (a simple modular architecture research tool) program (http://smart.embl-heidelberg.de/). The amino acid sequence alignment was performed with MegAlign in DNAstar 7.0 using the method of ClustalW. Prediction of theoretical signal peptide and transmembrane domain was conducted using SignalP 4.1 (http://www.cbs.dtu. $\mathrm{dk} /$ services/SignalP/). Multiple sequence alignment was conducted using DNAMAN. The phylogenetic tree was generated based on the deduced amino acid sequences using the Neighbour-Joining method with MEGA6.0. All sequences used for the phylogenetic analysis were listed in Table 2.

Table 1 List of primer sequences used in the study

\begin{tabular}{|c|c|c|}
\hline Name & Sequence & Application \\
\hline PGRP5-F & 5'-CCTCAGCTCGCTCACATCCA-3' & cDNA amplification \\
\hline PGRP5-R & 5'-AGAGTATAAATGTTCCCCCGGA-3' & \\
\hline PGRP6-F & 5'-GTGTACACTCTCTCTGGTITGC-3' & \\
\hline PGRP6-R & 5'-CTGGTAACGCTCCCATGTCTGG-3' & \\
\hline$\beta$-actin- $F$ & 5'-TGGCATCACACCTTCTACAAC-3' & \\
\hline$\beta$-actin-R & 5'-GCCCATCTCCTTGCTCGAAGTC-3' & \\
\hline 5'RACE Outer primer & 5'-CATGGCTACATGCTGACAGCCTA-3' & RACE gene specific primers \\
\hline 5'RACE Inner primer & 5'-CGCGGATCCACAGCCTACTGATGATCAGTCGATG-3' & \\
\hline 3'RACE Outer primer & 5'-TACCGTCGTTCCACTAGTGATTT-3' & \\
\hline 3'RACE Inner primer & 5'-CGCGGATCCTCCACTAGTGATTTCACTATAGG-3' & \\
\hline 5' PGRP5 Outer primer & 5'-TGGATGTGAGCGAGCTGAGGGACG-3' & \\
\hline 5' PGRP5 Inner primer & 5'-ATCACAGTCTGTGCGGGACTCTTC-3' & \\
\hline 3' PGRP5 Outer primer & 5'-CGTCCCTCAGCTCGCTCACATCCA-3' & \\
\hline 3' PGRP5 Inner primer & 5'-GGAGATGGGATGGTGTATGAAGGG-3' & \\
\hline 5' PGRP6 Outer primer & 5'-GTAACTCTTCAGCAGGTCACTCAG-3' & \\
\hline 5' PGRP6 Inner primer & 5'-AACTTCTGACCCGAGAATGAACCC-3' & \\
\hline 3' PGRP6 Outer primer & 5'-CAAGAGTGCGATGGACATGGTGAG-3' & \\
\hline 3' PGRP6 Inner primer & 5'-GTCTTCATCATACTCCTTATACGG-3' & \\
\hline PGRP5-qF & 5'-CCTCAGCTCGCTCACATCCA-3' & Primers for Real-time PCR \\
\hline PGRP5-qR & 5'-CGCCCTTCATACACCATCCC-3' & \\
\hline PGRP6-qF & 5'-ATGGTGAGGTATGACTTC-3' & \\
\hline PGRP6-qR & 5'-CTTGTCTGTGTCCGTATA-3' & \\
\hline S11-F & 5'-CCGTGGGTGACATCGTTACA-3' & \\
\hline S11-R & 5'-TCAGGACATTGAACCTCACTGTCT-3' & \\
\hline
\end{tabular}

All the primer sequences used in gene clone and Real-time quantitative PCR of Ccpgrp5, Ccpgrp6 and internal reference gene 
Table 2 Sequences of peptidoglycan recognition protein used for phylogenetic tree construction and multiple sequence alignment

\begin{tabular}{|c|c|c|c|c|c|}
\hline Species & Protein & Accession no. & Species & Protein & Accession no. \\
\hline Homo sapiens & PGRP1 & NP_005082 & Drosophila melanogaster & PGRP-SA & NP_572727 \\
\hline Homo sapiens & PGRP2 & NP_443122 & Drosophila melanogaster & PGRP-SC1A & NP_610407 \\
\hline Homo sapiens & PGRP3 & NP_443123 & Drosophila melanogaster & PGRP-SD & NP_610410 \\
\hline Homo sapiens & PGRP4 & NP_065126 & Drosophila melanogaster & PGRP-LA & NP_996028 \\
\hline Mus musculus & PGRP1 & NP_033428 & Drosophila melanogaster & PGRP-LB & NP-731575 \\
\hline Mus musculus & PGRP2 & NP_067294 & Drosophila melanogaster & PGRP-LC & NP_729468 \\
\hline Mus musculus & PGRP3 & NP_997130 & Drosophila melanogaster & PGRP-LD & NP_001027113 \\
\hline Mus musculus & PGRP4 & NP_997146 & Drosophila melanogaster & PGRP-LE & NP-573078 \\
\hline Danio rerio & PGRP2 & NP_001038631 & Drosophila melanogaster & PGRP-LF & NP_648299 \\
\hline Danio rerio & PGRP5 & NP_001037786 & Sebastes schlegeli & PGRP-L2 & GU126381 \\
\hline Danio rerio & PGRP6 & NP_001038687 & Argopecten irradians & PGRP & AAR92030 \\
\hline Chlamys farreri & PGRP-S1 & AAY53765 & Euprymna scolopes & PGRP1 & AAY27973 \\
\hline Asterias rubens & PGRP-S1a & ABB04459 & Euprymna scolopes & PGRP2 & AAY27974 \\
\hline Asterias rubens & PGRP- S2a & ABB04460 & Euprymna scolopes & PGRP3 & AAY27975 \\
\hline Canislupus familiaris & PGRP2 & XP-852999 & Euprymna scolopes & PGRP4 & AAY27976 \\
\hline Sus scrofa & PGRP1 & NP-001001260 & Ornithorhynchusanatinus & PGRP-L & XP-001506175 \\
\hline Sus scrofa & PGRP-L & NP-998903 & Ornithorhynchusanatinus & PGRP2 & XP-001520922 \\
\hline Gallus gallus & PGRP2 & NP-001038151 & Bos Taurus & PGRP1 & AAL87002 \\
\hline Equus caballus & PGRP4 & XP-001494309 & Bos Taurus & PGRP2 & DAA19524 \\
\hline Sciaenop ocellatus & PGRP2 & ACJ13032 & Bos Taurus & PGRP3 & XP-611696 \\
\hline Tetraodonnigroviridis & PGRP-L & CAG06114 & Bos Taurus & PGRP4 & XP-874055 \\
\hline Chlamys farreri & PGRP-S1 & AAY53765 & Macaca mulatta & PGRP1 & XP_001103121 \\
\hline Ctenopharyngodon idella & PGRP5 & AFE48096 & Macaca mulatta & PGRP3 & XP_001110242 \\
\hline Ctenopharyngodon idella & PGRP6 & ADL41186 & Rattus norvegicus & PGRP1 & AAF73252 \\
\hline Camelus dromedarius & PGRP1 & CAC84130 & Rattus norvegicus & PGRP3 & XP_008759474 \\
\hline Xenopus tropicalis & PGRP1 & NP_001015775 & Trichoplusia ni & PGRP & O76537 \\
\hline Xenopus tropicalis & PGRP2 & $\mathrm{ABO} 15681$ & Anoplopoma fimbria & PGRP-SC2 & ACQ58764 \\
\hline Oreochromis niloticus & PGRP-SC2 & XP_003441739 & Azumapecten farreri & PGRP-S1 & AAY53765 \\
\hline Saimo rerio & PGRP-S & NP-001037786 & Sebastes schlegelii & PGRP-L & ADC93708 \\
\hline Pongo abelii & PGRP1 & XP-002829481 & Monodelphis domestica & PGRP1 & XP-001363587 \\
\hline Monodelphis domestica & PGRP3 & XP-007481978 & Salmo salar & PGRP-S & ВТ049722 \\
\hline
\end{tabular}

\section{Real-time quantitative PCR}

Real-time quantitative PCR was performed with a LightCycler 96 Real-Time PCR System (Roche) using SYBR Green Real Master Mix (Tiangen). General cycling conditions were set to: incubation at $95^{\circ} \mathrm{C}$ for $3 \mathrm{~min}$, followed by 40 cycles for $10 \mathrm{~s}$ at $95^{\circ} \mathrm{C}, 30 \mathrm{~s}$ at $62^{\circ} \mathrm{C}$ and $20 \mathrm{~s}$ at $72^{\circ} \mathrm{C}$. The comparison between the internal reference gene $40 \mathrm{~S}$ ribosomal protein $\mathrm{S} 11$ and $\beta$-actin by BestKeeper gave decreasing ranking order for $\mathrm{S} 11$ and $\beta$-actin (http://150.216.56.64/referencegene.php?type=reference) [46]. Expression of mRNA was normalized with the expression of $40 \mathrm{~S}$ ribosomal protein S11 in each sample. The Relative expression was determined using the $2^{(-\Delta \Delta \mathrm{Ct})}$ method $[39,47]$. The primers for Ccpgrp5 and Ccpgrp6 are shown in Tables 1 and 2 respectively. The efficiencies of each primers for Ccpgrp5, Ccpgrp6 and internal reference gene S11 were 95.78, 100.67 and $99.43 \%$ respectively. Each PCR was performed with triplicate samples.

\section{Statistical analysis}

The significance of the average fold change between the challenged group and the control group were analyzed using the Graphpad Prism 6. The significant differences were considered at $p<0.05$. A two-way analysis of variance (ANOVA) was performed to test differences in gene expression in each tissue. 


\section{Abbreviations}

ANOVA: Two-way analysis of variance; DAP: Diaminopimelic acid; dpf: Days post fertilization; Imd: Immune deficiency signal transduction pathways; LPS: Lipopolysaccharide; MurNAc: N-acetylmuramic acid; ORF: Open reading frame; PAMPs: Pathogen-associated molecular patterns; PGLYRP-2 (PGLYRP-1, PGLYRP-3, PGLYRP-4): Peptidoglycan recognition proteins; PGRP: Peptigoglycan recognition protein; PI: Isoelectric point; proPO: Prophenoloxidase; PRRs: Pattern recognition receptors; RACE: Rapid amplification of the CDNA ends; SDS-PAGE: Sodium dodecyl sulfate polyacrylamide gel electropheresis; SMART: A simple modular architecture research tool; UTR: Untranslated region

\section{Acknowledgements}

Not applicable.

\section{Funding}

This work was supported by grants (ZR2014CQ051 and ZR2014CZ004) of Natural Science Foundation of Shandong Province (CN) and National Natural Science Foundation of China (CN) (No: 31602186). The funders paid for the study to be performed and for the page charges for this article.

\section{Availability of data and materials}

The dataset supporting the conclusions of this article is available in the GenBank (https://www.ncbi.nlm.nih.gov/nuccore/MF818332) and the accession number is MF6818332, (https://www.ncbi.nlm.nih.gov/nuccore/ MG272264) and the accession number is MG272264.

\section{Authors' contributions}

FMZ and GWY participated in the design of the study, performed the experiments, collected and analysed data, and drafted the manuscript. YHZ and YW cloned and sequenced the CCPGRP5 and CCPGRP6 genes and Realtime quantitative PCR. XYX, SJS and MY conceived the study and participated in its design and coordination. All authors read and approved the final manuscript.

\section{Ethics approval}

The protocol was approved by the Animal Experimental Ethics Committee of Shandong Normal University (Permit Number: AEECSDNU2017004).

\section{Consent for publication}

Not applicable.

\section{Competing interests}

The authors declare that they have no competing interests.

\section{Publisher's Note}

Springer Nature remains neutral with regard to jurisdictional claims in published maps and institutional affiliations.

Received: 2 July 2018 Accepted: 11 December 2018

Published online: 07 January 2019

\section{References}

1. Shan S, Liu D, Liu R, Zhu Y, Li T, Zhang F, An L, Yang G, Li H. Nonmammalian toll-like receptor 18 (Tlr18) recognizes bacterial pathogens in common carp (Cyprinus carpio L.): indications for a role of participation in the NF-kappaB signaling pathway. Fish Shellfish Immunol. 2018:72:187-98.

2. Z Zhang F, Liu D, Wang L, Li T, Chang Q, An L, Yang G. Characterization of IgM-binding protein: a plgR-like molecule expressed by intestinal epithelial cells in the common carp (Cyprinus carpio L.). Vet Immunol Immunopathol. 2015;167(1-2):30-5.

3. Rombout JH, Yang G, Kiron V. Adaptive immune responses at mucosal surfaces of teleost fish. Fish Shellfish Immunol. 2014;40(2):634-43.

4. Magnadottir B. Innate immunity of fish (overview). Fish Shellfish Immunol. 2006;20(2):137-51

5. Dziarski R. Peptidoglycan recognition proteins (PGRPS). Mol Immunol. 2004; 40(12):877-86

6. Dziarski R, Royet J, Gupta D. Peptidoglycan recognition proteins and lysozyme. Encycl Immunobiol. 2016;2:15.
7. Chen K, Liu C, He Y, Jiang H, Lu Z. A short-type peptidoglycan recognition protein from the silkworm: expression, characterization and involvement in the prophenoloxidase activation pathway. Dev Comp Immunol. 2014;45(1):1-9.

8. Yoshida $H$, Kinoshita $K$, Ashida M. Purification of a peptidoglycan recognition protein from hemolymph of the silkworm, Bombyx mori. J Biol Chem. 1996;271(23):13854-60.

9. Tydell CC, Yount N, Tran D, Yuan J, Selsted ME. Isolation, characterization, and antimicrobial properties of bovine oligosaccharide-binding protein. A microbicidal granule protein of eosinophils and neutrophils. J Biol Chem. 2002;277(22):19658-64.

10. Sang Y, Ramanathan B, Ross CR, Blecha F. Gene silencing and overexpression of porcine peptidoglycan recognition protein long isoforms: involvement in beta-defensin-1 expression. Infect Immun. 2005;73(11):7133-41.

11. Li JH, Chang MX, Xue NN, Nie P. Functional characterization of a short peptidoglycan recognition protein, PGRP5 in grass carp Ctenopharyngodon idella. Fish Shellfish Immunol. 2013;35(2):221-30

12. Qi Z, Ren S, Zhang Q, Zou J, Xu Q, Wang Z, Qiao G, Nie P, Chang M. Functional characterization of a short peptidoglycan recognition protein from Chinese giant salamander (Andrias davidianus). Oncotarget. 2017;8(59): 99323-35.

13. Dziarski R, Gupta D. Mammalian PGRPs: novel antibacterial proteins. Cell Microbiol. 2006;8(7):1059-69.

14. Kashyap DR, Wang M, Liu LH, Boons GJ, Gupta D, Dziarski R. Peptidoglycan recognition proteins kill bacteria by activating protein-sensing twocomponent systems. Nat Med. 2011;17(6):676-83.

15. Dziarski R, Gupta D. Review: mammalian peptidoglycan recognition proteins (PGRPs) in innate immunity. Innate Immun. 2010;16(3):168-74.

16. Chang MX, Nie P, Wei LL. Short and long peptidoglycan recognition proteins (PGRPs) in zebrafish, with findings of multiple PGRP homologs in teleost fish. Mol Immunol. 2007;44(11):3005-23.

17. Chang MX, Nie P. RNAi suppression of zebrafish peptidoglycan recognition protein 6 (ZfPGRP6) mediated differentially expressed genes involved in toll-like receptor signaling pathway and caused increased susceptibility to Flavobacterium columnare. Vet Immunol Immunopathol. 2008;124(3-4):295-301.

18. Kim MY, Jang JH, Lee JW, Cho JH. Molecular cloning and characterization of peptidoglycan recognition proteins from the rockfish, Sebastes schlegeli. Fish Shellfish Immunol. 2010;28(4):632-9.

19. Choi KM, Joo MS, Cho DH, Bae JS, Jeong JM, Woo WS, Han HJ, Lee DC, Cho $\mathrm{MY}$, Jung $\mathrm{SH}$, et al. Molecular characterization, expression and functional analysis of peptidoglycan recognition protein-SC2 from rock bream, Oplegnathus fasciatus. Fish Shellfish Immunol. 2018;77:286-93.

20. Mao Y, Wang J, Zhang Z, Ding S, Su Y. Cloning, mRNA expression, and recombinant expression of peptidoglycan recognition protein II gene from large yellow croaker (Pseudosciaena crocea). Mol Biol Rep. 2010; 37(8):3897-908.

21. Sun L, Liu S, Wang R, Li C, Zhang J, Liu Z. Pathogen recognition receptors in channel catfish: IV. Identification, phylogeny and expression analysis of peptidoglycan recognition proteins. Dev Comp Immunol. 2014;46(2):291-9.

22. Li JH, Yu ZL, Xue NN, Zou PF, Hu JY, Nie P, Chang MX. Molecular cloning and functional characterization of peptidoglycan recognition protein 6 in grass carp Ctenopharyngodon idella. Dev Comp Immunol. 2014;42(2):244-55

23. Yu ZL, Li JH, Xue NN, Nie P, Chang MX. Expression and functional characterization of PGRP6 splice variants in grass carp Ctenopharyngodon idella. Dev Comp Immunol. 2014;47(2):264-74.

24. Jang $\mathrm{JH}, \mathrm{Kim} \mathrm{H}, \mathrm{Cho} \mathrm{JH}$. Molecular cloning and functional characterization of peptidoglycan recognition protein OMPGRP-L2 from the rainbow trout, Oncorhynchus mykiss. Vet Immunol Immunopathol. 2017;192:28-32.

25. Jang $\mathrm{JH}, \mathrm{Kim} \mathrm{H}, \mathrm{Cho} \mathrm{JH}$. Rainbow trout peptidoglycan recognition protein has an anti-inflammatory function in liver cells. Fish Shellfish Immunol. 2013; 35(6):1838-47

26. Zhang L, Gao C, Liu F, Song L, Su B, Li C. Characterization and expression analysis of a peptidoglycan recognition protein gene, SMPGRP2 in mucosal tissues of turbot (Scophthalmus maximus L.) following bacterial challenge. Fish Shellfish Immunol. 2016;56:367-73.

27. Sun QL, Sun L. A short-type peptidoglycan recognition protein from tongue sole (Cynoglossus semilaevis) promotes phagocytosis and defense against bacterial infection. Fish Shellfish Immunol. 2015:47(1):313-20.

28. Li MF, Zhang M, Wang CL, Sun L. A peptidoglycan recognition protein from Sciaenops ocellatus is a zinc amidase and a bactericide with a substrate range limited to gram-positive bacteria. Fish Shellfish Immunol. 2012;32(2):322-30. 
29. Del Castillo CS, Hikima J, Jang HB, Nho SW, Jung TS, Wongtavatchai J, Kondo H, Hirono I, Takeyama H, Aoki T. Comparative sequence analysis of a multidrug-resistant plasmid from Aeromonas hydrophila. Antimicrob Agents Chemother. 2013;57(1):120-9.

30. Majumdar T, Datta S, Ghosh D, Dutta S, Chakraborty A, Goswami R, Mazumder S. Role of virulence plasmid of Aeromonas hydrophila in the pathogenesis of ulcerative disease syndrome in Clarias batrachus. Indian J Biochem Biophys. 2007;44(5):401-6.

31. Janda JM, Abbott SL. The genus Aeromonas: taxonomy, pathogenicity, and infection. Clin Microbiol Rev. 2010;23(1):35-73.

32. Gupta D. Peptidoglycan recognition proteins-maintaining immune homeostasis and normal development. Cell Host Microbe. 2008;3(5):273-4.

33. Wei X, Yang J, Yang D, Xu J, Liu X, Yang J, Fang J, Qiao H. Molecular cloning and mRNA expression of two peptidoglycan recognition protein (PGRP) genes from mollusk Solen grandis. Fish Shellfish Immunol. 2012;32(1):178-85.

34. Valero Y, Morcillo P, Meseguer J, Buonocore F, Esteban MA, Chaves-Pozo E, Cuesta A. Characterization of the IFN pathway in the teleost fish gonad against vertically transmitted viral nervous necrosis virus. J Gen Virol. 2015; 96(8):2176-87.

35. Zhu YY, Xing WX, Shan SJ, Zhang SQ, Li YQ, Li T, An L, Yang GW. Characterization and immune response expression of the rig--like receptor mda5 in common carp Cyprinus carpio. J Fish Biol. 2016;88(6):2188-202.

36. Li H, Yang GW, Ma F, Li T, Yang HT, Rombout J, An LG. Molecular characterization of a fish-specific toll-like receptor 22 (TLR22) gene from common carp (Cyprinus carpio L.): evolutionary relationship and induced expression upon immune stimulants. Fish Shellfish Immunol. 2017;63:74-86.

37. Li T, Li H, Peng S, Zhang F, An L, Yang G. Molecular characterization and expression pattern of $X$ box-binding protein-1 (XBP1) in common carp (Cyprinus carpio L.): indications for a role of XBP1 in antibacterial and antiviral immunity. Fish Shellfish Immunol. 2017;67:667-74.

38. Shan SJ, Liu DZ, Wang L, Zhu YY, Zhang FM, Li T, An LG, Yang GW. Identification and expression analysis of irak1 gene in common carp Cyprinus carpio L.: indications for a role of antibacterial and antiviral immunity. J Fish Biol. 2015;87(2):241-55.

39. Zhu YY, Qi CC, Shan SJ, Zhang FM, Li H, An LG, Yang GW. Characterization of common carp (Cyprinus carpio L.) interferon regulatory factor 5 (IRF5) and its expression in response to viral and bacterial challenges. BMC Vet Res. 2016;12(1):127.

40. Li H, Guo H, Shan S, Qi C, An L, Yang G. Characterization and expression pattern of a novel beta-defensin in common carp (Cyprinus carpio L.) implications for its role in mucosal immunity. Biosci Biotechnol Biochem. 2014;78(3):430-7.

41. Li H, Li T, Guo Y, Li Y, Zhang Y, Teng N, Zhang F, Yang G. Molecular characterization and expression patterns of a non-mammalian toll-like receptor gene (TLR21) in larvae ontogeny of common carp (Cyprinus carpio L.) and upon immune stimulation. BMC Vet Res. 2018:14(1):153.

42. Liu TT, Liu S, Ma L, Li FL, Zheng ZD, Chai RF, Hou YH, Xie YB, Li GR. Oogenesis, vitellogenin-mediated ovarian degeneration and immune response in the annual fish Nothobranchius guentheri. Fish Shellfish Immunol. 2017;66:86-92.

43. Yang G, Guo H, Li H, Shan S, Zhang X, Rombout JH, An L. Molecular characterization of LEAP-2 CDNA in common carp (Cyprinus carpio L.) and the differential expression upon a Vibrio anguillarum stimulus; indications for a significant immune role in skin. Fish Shellfish Immunol. 2014;37(1):22-9.

44. Shan S, Qi C, Zhu Y, Li H, An L, Yang G. Expression profile of carp IFN correlate with the up-regulation of interferon regulatory factor-1 (IRF-1) in vivo and in vitro: the pivotal molecules in antiviral defense. Fish Shellfish Immunol. 2016;52:94-102.

45. Li T, Shan S, Wang L, Yang G, Zhu J. Identification of a fish-specific NOD-like receptor subfamily C (NLRC) gene from common carp (Cyprinus carpio L.): characterization, ontogeny and expression analysis in response to immune stimulation. Fish Shellfish Immunol. 2018;82:371-7.

46. Pfaffl MW, Tichopad A, Prgomet C, Neuvians TP. Deternimation of stable housekeeping genes, differentially regulated target genes and sample integrity: BestKeeper- excel-based tool using pair-wise correlations. Biotechnol Lett. 2004:26:509-15.

47. Livak KJ, Schmittgen TD. Analysis of relative gene expression data using realtime quantitative $P C R$ and the $2(-$ detla delta $C(T))$ method. Methods. 2001;25:402-8.

Ready to submit your research? Choose BMC and benefit from:

- fast, convenient online submission

- thorough peer review by experienced researchers in your field

- rapid publication on acceptance

- support for research data, including large and complex data types

- gold Open Access which fosters wider collaboration and increased citations

- maximum visibility for your research: over $100 \mathrm{M}$ website views per year

At $\mathrm{BMC}$, research is always in progress.

Learn more biomedcentral.com/submissions 